\title{
Apresentação \\ O Governo dos negócios: comércio, instituições e seus agentes entre os séculos XVIII e XIX
}

\section{Presentation}

The Government of Business: Commerce, Institutions

and their Agents between 18th and 19th centuries

Simona CERUTTI

A investigação sobre as origens do direito dos comerciantes, os debates em torno de sua datação mais ou menos recuada no tempo, as pesquisas das primeiras citações nas obras dos juristas do século XVI, ocuparam durante muito tempo os historiadores entre a Idade Média e a Era Moderna. O desafio era identificar o momento em que um mundo à parte teria sido criado e o comércio teria ganho uma relativa autonomia em relação a outras esferas da vida social, estruturando assim suas próprias instituições e ditando suas próprias regras. Essa investigação sobre as origens foi sem dúvida incentivada pelo desejo de legitimação das elites comerciais que, sobretudo no século XVIII e em várias situações na Europa e para além dela, manifestou-se de maneira particularmente urgente nos contextos frequentemente ferozes de disputas políticas dentro dos governos. Seus argumentos em torno da irredutível especificidade do universo do comércio e da necessidade de garantir-lhe um lugar privilegiado encontrou um público atento e sensível entre os historiadores

* https://orcid.org/0000-0001-7427-7430

LaDéHiS (Laboratoire de Démographie et Histoire Sociale), EHESS

54 boulevard Raspail, 75006, Paris, France

simona.cerutti@ehess.fr 
contemporâneos, nutrido pela experiência atual da chamada "autonomia" de esfera econômica em relação a outros domínios da vida social.

Algumas pesquisas fundamentais contribuíram, nos últimos anos, para mudar essa situação e abriram caminho para questionamentos mais aprofundados. Por um lado, todo um ramo de estudos sobre o que podemos definir como "os léxicos econômicos" das sociedades medievais e modernas lançou uma nova luz sobre as relações entre economia, direito, religião, que mostraram sua estreita conexão. Nos trabalhos de Bartolomé Clavero (1991) ou de Giacomo Todeschini (2002) trata-se menos de identificar as raízes religiosas da economia do que mostrar em que medida os dois domínios são construídos com o mesmo material, pois seus conceitos estão baseados nos mesmos princípios. As palavras contrato, troca, dívida, crédito, juro... estão carregadas dessa pluralidade de significados devido a seu caráter anfíbio, em que toda separação entre questões materiais e questões morais ou jurídicas seria paradoxal. Nesse contexto, toda "autonomia" ou especificidade irredutível do campo econômico mostra seu caráter anacrônico; e a pesquisa sobre a "cultura do negócio" se abre a uma pluralidade de domínios frequentemente inesperados.

Outro movimento que contribuiu para "libertar" a esfera econômica dos limites que tinham sido construídos em torno dela foi a maior atenção em relação a um tema aparentemente técnico, o dos modos de resolução de conflitos e do procedimento judicial seguido nos tribunais dedicados aos casos comerciais (AGO; CERUTTI, 1999). $\mathrm{O}$ terreno era delicado porque, como acabamos de mencionar, o direito e a justiça eram os domínios em que a busca pela originalidade na esfera econômica era mais desenvolvida. $\mathrm{O}$ direito em vigor nos tribunais que lidavam com esses casos era visto como um ramo separado do direito, mesmo em períodos em que essa separação não estava prevista e nem era buscada pelos contemporâneos. Essa abordagem limitou a compreensão dos princípios que regiam esses procedimentos judiciais, cujas características - a brevidade, os custos mitigados, a ausência de advogados, importância das provas escritas, etc. - estavam relacionadas principalmente às exigências do comércio. Trata-se de um daqueles 
casos em que o resultado de um processo reconstrói, no sentido contrário, sua própria história. De fato, é sabido que o próprio conceito de ius mercatorum apareceu na verdade tardiamente, em pleno século XVI: anteriormente, as bibliotecas dos juristas falavam apenas de clérigos, professores, aprendizes, camponeses, soldados, viúvas, menores, e a condição jurídica do comerciante era difícil de distinguir daquela que caracterizava o grupo de pessoas que gozavam do mesmo regime de derrogação. Na mesma ordem de ideias, algumas décadas atrás alguns autores alertaram para perspectivas demasiado estreitas que tendiam a confinar o ius mercatorum em um espaço dedicado, negligenciando assim as relações que o vinculavam aos direitos e privilégios que uniam, na Idade Média, as diferentes figuras da itinerância.

$\mathrm{E}$, de fato, na origem dessa nova consideração do lugar do mundo do comércio nas configurações sociais dos diferentes países, havia também uma constatação importante: o fato de que o procedimento judicial seguido por um grande número de tribunais de comércio durante toda a Era Moderna tinha uma tradição antiga e estava longe de se limitar apenas aos comerciantes. O procedimento sumário - como era denominado em uma pluralidade de situações territoriais (CERUTTI, 2003) - era aquele ao qual tinham direito diferentes figuras sociais que compartilhavam uma debilidade específica, uma relativa incompetência das normas locais relacionada tanto à fragilidade de seus estatutos (e de sua capacidade de agir diretamente na justiça; viúvas, menores, etc.) quanto à mobilidade no território (comerciantes, soldados, peregrinos, empregados, etc.). A justiça sumária também era chamada de justiça para "os miseráveis", isto é, os estrangeiros, os pobres, as viúvas, os menores, os órfãos, os camponeses, os soldados, os empregados, os peregrinos e, finalmente, os comerciantes. A "sumária” era, portanto, o procedimento que poderia ser administrado pontualmente por certo número de tribunais, para além daqueles destinados aos atos comerciais. No caso do Estado da Saboia, por exemplo (do qual tratou minha própria pesquisa), o rito sumário era aquele seguido pelo Senado do Piemonte para resolver os assuntos das viúvas e dos menores, ou ainda aquele seguido pelo Vigário para resolver os diferendos relativos 
aos empregados. Tal procedimento permitia o acesso direto à justiça (sem seus advogados, sem seus custos) por parte de uma população que compartilhava uma fragilidade devida a uma menor inscrição social. Esse procedimento deve ser inscrito, de fato, no quadro mais geral das justiças "derrogatórias" das formalidades do processo, caracterizadas por um arbitrium procedendi (MECCARELLI, 1998); se, no caso dos procedimentos inquisitoriais, por exemplo, o rito sumário remete à maior liberdade do juiz, livre da figura iudicii, no contexto judicial dos tribunais comerciais o arbitrium se traduzia pela maior possibilidade de ação das partes, expressa, aliás, na fórmula consagrada: ser “juiz em seu próprio processo".

No entanto, reinserir a justiça dos comerciantes no panorama das justiças urbanas significa, ao mesmo tempo, ocultar sua irredutível originalidade e revelar a riqueza da cultura jurídica dessas sociedades da Era Moderna. Assim, somos confrontados a esse pluralismo jurídico que caracterizou uma parte da nossa história e, portanto, às condições de convivência, dentro da mesma sociedade, de várias maneiras de conceber o justo e de administrá-lo. ${ }^{1}$

Várias ideias de justiça podiam coexistir no mesmo espaço e no mesmo lugar, que podiam ser moduladas em função das fisionomias sociais do público ao qual essas justiças se dirigiam. Isso nos introduz à dialética existente nessas sociedades modernas entre diferentes fontes de direito, bem como entre diferentes tradições jurídicas que compunham a construção heterogênea do direito comum. Em relação à justiça comum, a "sumária" nos introduz a uma articulação diferente da relação entre caso e série; entre fatos e direitos; e finalmente aos diferentes elementos que constituem a gramática do vínculo social vigente no campo judicial.

Finalmente, o último ponto de inflexão que abriu uma nova consideração sobre o lugar ocupado pelo mundo do comércio nas sociedades da era moderna, colocando em discussão, mais uma vez, a suposta "autonomia", foi inaugurado por esses trabalhos que reivindicavam sua

1 A mais recente elaboração é de HERZOG (no prelo). 
filiação à economia neoinstitucionalista. ${ }^{2}$ Como se sabe, a reflexão enfocou o papel desempenhado por uma pluralidade de instituições (mais ou menos formalizadas, das corporações aos tribunais, aos Consulados, aos árbitros privados...) na construção de relações de confiança e na produção de certificações capazes de reduzir a incerteza das trocas, ocorrendo em sociedades caracterizadas por sistemas de informação muito incompletos. A consideração das características próprias às economias e aos mercados da Era Moderna e das condições de incerteza em que as trocas aconteciam abriu caminho para uma nova atenção em relação a esse panorama institucional que, muito longe de ser apenas o cenário dessas trocas, tinha desempenhado claramente um papel essencial em sua realização.

Juntos, portanto, esses diferentes movimentos - a consideração das relações existentes entre direito, religião, economia e mercado; a consideração das modalidades de resolução de conflitos e da variedade de instituições que foram criadas e convocadas para garantir o sucesso das transações - mudaram definitivamente o nosso conhecimento do mundo do comércio e, de maneira mais geral, do funcionamento da economia da Era Moderna.

A coletânea de ensaios que se segue é uma excelente prova do novo momento que se abriu para esses estudos. Cada um dos seis artigos aborda um tema que evocamos. O ensaio de Guillermina del Valle Pavón nos mostra como o campo da economia e o da devoção se encontraram e se reforçaram mutuamente; as práticas de crédito adotadas pelos grandes comerciantes da Cidade do México no fim do século XVIII baseavam-se na criação de "capellanías", portanto, de fundações religiosas, cujos bens constituíam meios de construção de redes úteis para o comércio. Em outras palavras, o terreno do investimento financeiro e o do investimento devocional estão estreitamente ligados, manifestando assim "a articulação complexa que existia entre a cultura

2 A referência obrigatória é o trabalho de NORTH (1990). 
católica e a reprodução social das redes de negócios no Antigo Regime novo-hispânico". ${ }^{3}$ Mais uma vez, trata-se menos de destacar comportamentos "oportunistas" por parte das pessoas no comércio do que enfatizar as imbricações de culturas familiares, comerciais e devocionais nessas sociedades da Era Moderna, o que torna anacrônico qualquer leitura disciplinar desses três domínios.

Por outro lado, duas das contribuições abordam um tema cuja importância acabamos de mensurar, o das formas institucionais que eram componentes essenciais do funcionamento do comércio em uma pluralidade de situações sociais. O ensaio de Javier Kraselsky, que traça as vicissitudes do Consulado de Comércio de Buenos Aires entre os séculos XVIII e XIX, mostra a importância dessa instituição na definição das políticas da coroa desde o início e depois dos governos revolucionários; enquanto o caso das corporações lusitanas analisado por Miguel Dantas da Cruz destaca o papel ativo que essas desempenharam no panorama urbano mesmo depois do terremoto de 1755 e pelo menos até as primeiras décadas do século XIX (contra a imagem corrente da decadência que teriam sofrido instituições que a historiografia frequentemente pintou como conservadoras e hostis a qualquer avanço do comércio e da indústria).

Finalmente, os ensaios de Andréa Slemian e Cláudia Chaves enfrentam o tema das modalidades de resolução dos conflitos comerciais, das instituições responsáveis por esses fins e das relações entre os sistemas judiciais que essas propõem e a oferta jurisdicional mais ampla. No centro dessas pesquisas estão os árbitros que garantiam uma justiça "laica" para os diferendos comerciais no Portugal do século XVIII, propondo, assim, os princípios de uma justiça "entre pares"; e, por outro lado, a Real Junta de Comércio do Império Luso-Brasileiro, cuja produção jurisprudencial é objeto de uma análise inovadora.

3 Trad. livre: "la compleja articulación que había entre la cultura católica y la reproducción social de las redes de negocios en el Antiguo Régimen novohispano". 
Cada um desses ensaios é, em suma, uma contribuição essencial para esta nova consideração do lugar do comércio e da vida econômica que contribuiu decisivamente para questionar não apenas o passado das sociedades da Era Moderna, mas também o nosso presente.

Tradução: Alexandre Agabiti Fernandez

\section{REFERÊNCIAS BIBLIOGRÁFICAS}

AGO, Renata; CERUTTI, Simona. Procedure di giustizia. Quaderni Storici, v. 101, n. 2, p. 307-314, 1999.

CERUTTI, Simona. Giustizia sommaria. Pratiche e ideali di giustizia in una società di Ancien Regime (Torino XVIII secolo). Milão: Feltrinelli, 2003.

CLAVERO, Bartolomé. Antidora. Antropología Católica de la Economía Moderna. Milão: Giuffrè, 1991.

HERZOG, Tamar. Legal Pluralism. In: MIROW, Matthew; URIBE, Víctor (Eds.). A Companion to the Legal History of Latin America. Leiden: Brill (no prelo).

MECARELLI, Massimo. Arbitrium. Un aspetto sistematico degli ordinamenti giuridici in età di diritto comune. Milão: Giuffré, 1998.

NORTH, Douglass. Institutions, institutional change and economic performance. Cambridge: Cambridge University Press, 1990.

TODESCHINI, Giacomo. I Mercanti e il tempio. La società cristiana e il circolo virtuoso della ricchezza fra Medioevo ed età moderna. Bolonha: Il Mulino, 2002. 